\title{
A GEOMETRIA DO UNIVERSO: TEMPO E ESPAÇO EM AVALOVARA E EM 1Q84
}

\section{Cacio José Ferreira ${ }^{1}$}

Resumo: O presente artigo investiga comparativamente as obras Avalovara, de Osman Lins, e 1Q84, de Haruki Murakami, sob a perspectiva de especificidades dos discursos nos dois romances em contraste, buscando identificar traços de tempo e espaço comuns, significativos e relevantes que se estabelecem no terreno da criação e intertextualidade, a fim de, por meio do estudo aprofundado e do desvendamento das questões temporais e espaciais, perceber as diferenças, assim reconhecendo elementos fundantes do território literário dos autores, em suas searas criativas e ideológicas, que obviamente se conectam com todo o entorno - os seus tempos e os seus espaços. Dessa forma, compreendendo as relações quanto à questão temporal, espacial, à geometria, à duplicidade e aos textos, cada qual à sua maneira, localizando traços de similaridade na arquitetura das obras.

Palavras-chave: Osman Lins; Avalovara; Haruki Murakami; 1Q84; Espaço e tempo.

\begin{abstract}
This paper investigates comparatively the literary works Avalovara, by Osman Lins and $1 Q 84$, by Haruki Murakami, from the perspective of specific speeches in the two novels in contrast, seeking to identify meaningful and relevant common perspectives on space and time, established in the field of creation and intertextuality in order to, understand the differences, by means of in-depth study and revealing the temporal and spatial issues, thereby recognizing the founding elements of the literary realm of the authors in their creative and ideological grainfields, which obviously connect with all the surroundings - their times and their spaces. Thus, understanding the relationships on the temporal matter, space, geometry, duplicity and texts, each in their own way, finding traces of similarity in the construction of the literary works.
\end{abstract}

Keywords: Osman Lins; Avalovara; Haruki Murakami; 1Q84; Space and time.

\section{Introdução}

Do escritor pernambucano Osman Lins (1924-1978), Avalovara (1973) é considerado um dos mais engenhosos romances da literatura brasileira. Nele,

1 Mestre em Literatura pela Universidade de Brasília e professor de Letras - Língua e Literatura Japonesa da Universidade Federal do Amazonas (UFAM) - Manaus-AM - Brasil; caciosan@hotmail.com. 
o foco narrativo oferece muitos caminhos de acesso e não fixa a contemplação dos acontecimentos em um determinado ponto do tempo e do espaço "permitindo ao leitor adentrá-lo de diversas maneiras, mas que, no fundo, é rigorosamente arquitetada por um construtor onipresente, em perfeita consonância com a concepção de que a narrativa é uma cosmogonia" (NITRINI, 2010, p. 153).

A construção do texto de Osman Lins extrapola as possibilidades da arte ao suscitar uma torrente de imagens onde o leitor "é um indivíduo que trabalha com riscos" (LINS, 1979, p.216). Nesse sentido, os riscos aparecem e desaparecem na medida em que a geometria produz os contornos da tessitura do texto. A desatenção do leitor, mesma que por uma fração de segundos, deixa escapar traços importantes para o entendimento do romance. E apesar de ser incontestavelmente uma obra densa, parece ainda ser transparente devido às sensações transmitidas pelos personagens, conforme indica o escritor em uma entrevista à Revista Escrita: "parecem o chumbo e o vidro do romance" (LINS, 1979, p. 217). Dessa forma, as teias da narrativa de Avalovara constróem uma rede de conexões por meio de uma visão aperspectivista com o mundo que o circunda.

Tal emaranhado de fios que tecem a escritura e a ordem do mundo impele o leitor de Avalovara, a outra obra, a outro romance contemporâneo, igualmente envolto pelo tear das palavras: 1Q84 (2009), de Haruki Murakami. Desse modo, a confluência da arquitetura de mundos e espaços bem arquitetados, o estudo comparativo do tempo e do espaço em Avalovara face ao novo trabalho do japonês Haruki Murakami, 1Q84 - textos que, por sua vez, também oferecem reflexos de tempos e espaços formando, dessa forma, a autoconsciência do indivíduo em si, no pararelismo de mundos, de contruções humanas que se embriagam de elementos maravilhosos, de fragmentos resgatados do inconsciente, elaborando a geometria de espaços e de tempos, assemelhando-se, assim, ao brilho do sol nos vitrais, presente na narrativa de Osman Lins - criando uma anáclase. Em 1Q84, a realidade paralela também é uma refração, principalmente por meio do uso da imagem da lua. Uma lua que emite luz, mas diverge na cor ou se duplica, assemelhando-se a um cristal.

Em relação ao texto de Haruki Murakami, o teórico Fuminobu Murakami postula que ele representa "uma visão pós-moderna, e os seus personagens sentem-se confortáveis ao se distanciarem da racionalização extrema, das emoções que circundam a vida diária, favorecendo, assim, o desapego e a indiferença" (MURAKAMI, 2005, p. 22). Tal afirmação confirma que o distanciamento da realidade é realizado pela dupla engrenagem que brota do inconsciente dos personagens. Ainda não há uma nitidez na cor que chega aos olhos. A consciência do real só será notada após percorrer os caminhos geométricos tecidos nos textos de Murakami, sob a claridade das duas luas. Dessa forma, ao compararmos a arquitetura das luas de Haruki Murakami com os contornos geométricos de Osman Lins, abre-se mais uma possibilidade de entreleçamento do tempo e do espaço, de ambas as obras. Em torno dessa ideia, em Lima Barreto e o Espaço Romanesco, Osman Lins afirma: 
Move-se o homem e recorda o passado. Nada disto o pacifica ante o espaço e o tempo, entidades unas e misteriosas, desafios constantes à sua faculdade de pensar. Acessíveis à experiência imediata e esquivos às interrogações do espírito, sugerem - espaço e tempo - múltiplas versões, como se monstros fabulosos (...). A narrativa é um objeto compacto e inextrincável, todos os seus fios se enlaçam entre si e cada um reflete inúmeros outros (LINS, 1976, p. 63).

Portanto, é coerente o entrelamento dos romances na proposta do espaço e do tempo, conjugando-se as duas obras por meio do plano simbólico, entre o rigor de uma lógica política unilinear e irreversível da matemática e o campo da linguagem. A cosmogonia de Avalovara também figura na quadratura do mundo duplo de 1Q84. Tal ideia pode ser fundamentada na afirmação de Brunel, na obra Que é Literatura Comparada?: "notam-se em literaturas diferentes florescimentos análogos que não se explicam inteiramente pelo jogo das influências" (BRUNEL, 1997, p. 57). A correlação em ambas a obras existe por meio da escritura que se destaca pela geometria do universo presente no texto e pela anáclase que eclode de vitrais e luas.

Na obra de Haruki Murakami, assim como no romance de Osman Lins, a escrita configura-se como mediadora e criadora da força que move o universo da escritura - é a palavra e o seu tempo - a voz que esclarece, humaniza o inconsciente e conecta espaços e períodos, não simplesmente pela temática que se apresenta ou resguarda, mas principalmente pela linguagem que range pela força deslocada para corda que contorna o espaço geométrico das narrativas e se firma enquanto discurso literário, conforme esclarece Bakhtin:

Para o gênero romanesco, não é a imagem do homem em si que é característica, mas justamente a imagem de sua linguagem. Mas para que esta linguagem se torne precisamente uma imagem de arte literária, deve se tornar discurso das bocas que falam, unir-se à imagem do sujeito que fala (BAKHTIN, 2002, p. 138).

Portanto, espaço e tempo contornam e ligam-se à imagem dos personagens de $1 Q 84$ e Avalovara. A escada que Aomame desce, após deixar o táxi, leva à refração do mundo e o tapete, que é cenário da transfiguração da vida de Abel e a personagem sem nome, configura-se no paraíso.

\section{A geometria do tempo e do espaço}

Osman Lins e Haruki Murakami utilizam com precisão a linguagem simbólica traçando perfis nas narrativas e elaborando um universo observável, ou seja, tudo é pensado geometricamente. Nada foge ao espaço delineado. No entanto, a visão aperspectivista permite vários acessos ao mesmo ponto e, a partir do ponto central, 
várias possibilidades de percurso. A organização do cenário se expande e contorna a fala dos personagens, gerando assim, novas quadraturas. Nesse sentido, versando sobre o "nome do autor", sua qualidade referencial, que the concede identidade na linguagem e no estilo mesmo de seus traços, temos a partir de Foucault a seguinte formulação:

(...) um nome de autor não é simplesmente um elemento em um discurso (...) assegura uma função classificatória; tal nome permite reagrupar um certo numero de textos, delimitá-los, deles excluir alguns, opô-los a outros. (...) o nome do autor funciona para caracterizar um certo modo de ele ser do discurso: para um discurso, o fato de haver um nome de autor, o fato de que se possa dizer "isso foi escrito por tal pessoa", ou "tal pessoa é o autor disso", indica que esse discurso não é uma palavra cotidiana, indiferente, uma palavra que se afasta, que flutua e passa, uma palavra imediatamente consumível, mas que se trata de uma palavra que deve ser recebida de uma certa maneira e que deve, em uma dada cultura, receber um certo status.

Chegar-se-ia finalmente a ideia de que o nome do autor não passa, como o nome próprio, do interior de um discurso ao indivíduo real e exterior que o produziu, mas que ele corre, de qualquer maneira, aos limites dos textos, que ele os recorta, segue suas arestas, manifesta o modo de ser ou, pelo menos, que ele o caracteriza (FOUCAULT, 2001, p. 271).

A ruptura a que se refere pode ser a pista de reconhecimento das vozes nos textos e assim nestes se autoriza a contraposição e, partindo dela, a mediação. E, ainda, segundo a afirmação de Homi Bhabha,"as diferenças não podem ser negadas ou totalizadas porque ocupam de algum modo o mesmo espaço" (BHABHA, 2005, p. 247).

$\mathrm{O}$ escritor preocupado com a mediação e a escrita contesta e rompe normas, por seu turno, o tempo e o espaço, elemento de peculiar importância no solo literário que converge, harmonicamente, ação, personagens, o ir e vir, criando, desse modo, o caráter de um determinado setor da sociedade. Para Osman Lins,

(...) o espaço move constantemente o escritor a necessidade de romper normas, de constestar o que aparece assentado. Não seria, por exemplo, destituída de interesse uma narrativa na qual o espaço se construísse a partir da personagem. Tal narrativa, aliás, já tem o seu modelo no Gênesis e em outros mitos cosmogônicos (LINS, 1976, p. 72).

A partir desse raciocínio, a escada de uma rodovia, o voo iluminado do pássaro transparente que aparece próximo aos vitrais ou a lua dupla que Tengo observa no parque, enquanto faz perscrutação na memória, revelam pedaços de tempos e espaços, mas é exigida do leitor uma percepção aguçada e ele deve dispor da capacidade de 
decifrar, entender que o tempo e o espaço podem revelar até mesmo dos gestos, ainda que refratários, de um personagem. Assim como a memória, composta de fragmentos de tempos e instantes, os instantes de tempos são captados e oferecidos aos personagens para a concretização de sua interação social. Tudo se assemelha a uma fresta que rompe a realidade completa e interna do personagem e dá a ele a capacidade de se interagir com tempos e espaços concretos, mas que só é possível naquele momento e naquela fresta rompida. Nesse viés, Bergson enfatiza que

não bastam a sim mesmos, uma vez que o escoamento não implica uma coisa que se escoa e a passagem não pressupõe estados pela quais se passa: a coisa e o estado não são mais que instantâneos da transição artificialmente captados; e essa transição, a única que é naturalmente experimentada é a própria duração (BERGSON, 2006, p. 50).

Pensando na ideia acima, o inconsciente se rompe, captando os contornos dos objetos externos, a vida e os diversos caminhos que existem na palavra. Nesse sentido, o ato da escrita supõe escolhas, cissura da totalidade interna e a apreensão do tempo e do espaço externos - das mínimas às de grande porte - e, por cada uma delas, os relâmpagos imaginativos e criativos que compõem e delineiam os caminhos a ser vencidos pelos personagens, engendram a invenção e possibilitam a armação de um mundo que ainda assim não está pronto.

Porquanto, diante da página em branco, todas as possibilidades de construção da geometria da escrita; diante da consolidação do texto, a cosmogonia já traçada, a necessária inquietação de concluir em escalas imaginativas o mundo que se desvela e ordena a obra recém-criada. O universo ali ordenado condensa uma espécie de completude, permenado os texto de 1Q84 e de Avalovara.

Nesse viés, Osman Lins afirma: "O homem diante de uma página em branco é o homem mais livre do mundo" (LINS, 1979, p. 203). A palavra desenhada na página transforma-se em literária, converge se em tempo e espaço e não aceita a imposição de uma única verdade, mas conduz o escritor ao enquadramento do mundo sob múltiplas perfomances. Tal afirmação também condiz com o trabalho de Haruki Murakami. Blanchot amplia essas possibilidades ao afirmar que aquele que escreve

parece senhor de sua caneta, pode tornar-se capaz de um grande domínio sobre as palavras, sobre o que deseja fazê-las exprimir. Mas esse domínio consegue apenas colocá-lo e mantê-lo em contato com a profunda passividade em que a palavra, não sendo mais do que sua aparência e a sombra de uma palavra, nunca pode ser dominada nem mesmo apreendida, mantém-se inapreensível, o momento indeciso da fascinação (BLANCHOT, 1987, p. 15). 
De uma forma peculiar, Avalovara e 1Q84 fragmentam a leitura pela refração. Levam o leitor a ter vislumbres extraordinários e que podem causar a estranha sensação de que já é conhecido, embora seja absolutamente novo - e inovador. Talvez a convivência com um mundo literário caótico e ao mesmo tempo rigorosamente estruturado com a trama e com os elementos criados por Osman Lins e Haruki Murakami sejam, em parte, a causa disso. A linha S6, em Avalovara - A espiral e o quadrado - exterioriza essa realidade.

Chega assim, de experimento em experimento, à sua frase em ângulo, vista entre espelhos invisíveis que ao mesmo tempo a cortam e a completam - e que, gravada em pedra, reproduzida em pergaminhos, se difundirá pelo mundo, intrigando os que com ela se defrontam e que inutilmente pensam em desmontá-la, alterá-la, subtrair-lhe uma só letra, pois a frase nos fita como um olho, inviolável, circular na sua quadradura, tão perfeita que tocá-la é ferir uma pupila a golpes de estilete (LINS, 1973, p.32).

Por conseguinte, a construção do tempo e do espaço, em Avalovara e em 1Q84, em meio à quadradura da composição acontece pela via do preenchimento das páginas em branco e por meio da palavra criadora, revelando uma possibilidade de reflexão, assim como Blanchot propõe sobre a indeterminação do ele.

«Eles» é a maneira na qual (ele) se liberta do neutro tomando emprestado à pluralidade uma possibilidade de se determinar, por ali voltando comodamente à indeterminação, como se (ele) pudesse encontrar ali o índice suficiente que lhe fixaria um lugar, aquele, muito determinado, onde se inscreve todo indeterminado. (BLANCHOT, 1973, p. 10).

Em 1Q84, por exemplo, Haruki Murakami sobrepõe duas histórias. Dois mundos coexistem e invadem a mente de Aomame abrindo uma fenda najovem comum, aparentemente, que vive no Japão cumprindo a simultaneidade de trabalhos: preparadora física e assassina. No entanto, a determinação dupla de Aomame a torna quase indecifrável. A refração da consciência em fazer ou não o trabalho de privar da vida um indivíduo escreve nos contornos descritivos uma espécie de invólucro de segredos. Junto com a construção do cenário que faz debuxar o perfil dela, a Sinfonietta, de Janácek produz ondas que distorce o tempo e o espaço, tornando-os, aparentemente, disformes, porém muito bem organizados. Ainda em 1Q84, o mundo dos homens pequeninos se une ao mundo burocrático (política e economia) por meio de corpos humanos e da reescrita de um romance denominado A crisálida de ar. Novamente, o mundo maravilhoso se expande, rompe o envoltório, unindo-se ao cenário externo.

Ora, apesar de persarmos que $1 Q 84$, um livro devotado por uma leitura aparentemente menos densa, ao inverso de Avalovara, o leitor menos atento pode perder-se nos relampejos 
que iluminam os sulcos e apresentam os dois mundos fragmentados e unidos pelo romance construído dentro da narrativa. Assim, as rachaduras permitem sondar o tempo e o espaço dos romances brasileiro e japonês nas histórias pelo universo das palavras. Nos romances, um dos encontros que assume vulto acontece na linha A 19 - Roos e as cidades, de Avalovara, e na afirmação do personagem Tamaru, em 1Q84. Assim dizem:

Estudo a tal ponto o mapa de Londres, que já não vejo apenas seu traçado e nomes - Kingsway, Oxford St., Green Park, river Thames —, irias a própria cidade, real e imaginária, construída no quarto, ao longo da tarde, com pedras, fotografias, gravuras antigas, páginas de romances, clichês, telegramas de jornais. A vã caçada na Itália e coisas subsequentes fazem-me crer que não mais existe no mundo, com as suas três muralhas, incólume, a Cidade vista um dia (perto de mim e como situada à distância, pois não é muito maior que um vestido, e, tal um vestido bordado a ouro e pedras, mergulha na água calma e some) e que, portanto, acabaram as minhas buscas (LINS, 1973, p. 217).

Estamos a chegar ao fim do século XX, as coisas são muito diferentes do que eram no tempo de Tchékhov. Já não há carruagens puxadas a cavalo nem as mulheres usam espartilho. Não sei bem como, o mundo sobreviveu aos nazis, a bomba atômica, à música moderna. Até mesmo a forma dos romances alterou drasticamente. Não tens de te preocupar (MURAKAMI, 2012, p. 462 - Tomo III).

A lógica da criação osmaniana mantém-se coerente com o plano do autor, o que também ocorre com Haruki Murakami, apesar de países diferentes. Segundo afirmações de ambos, e os textos autorais assim confirmam, o relâmpagos abrem as fissuras e anunciam que o tempo e o espaço no romance direcionam para outro caminho. Ou simplesmente iluminam o cenário que circunda o personagem. A ele cabe escolher aquele que o olhar atento, rápido e geométrico captou no abrir da fissura e da refração das imagens. Por conseguinte, a matemática, a lógica e a geometria, bem como as dobras do degrau da escada, constituem-se em bases para as tramas. Assim, cabe ao indivíduo "manter-se informado sobre filosofia, belas-artes, história e política; e dotar-se de mobilidade no tempo e no espaço" (BRUNEL, 1995, p. 144).

\section{Conclusão}

Portanto, no rastro dos indicativos de duplicidade, visão mutiplicada, transformação e muito peculiarmente a entrada em um mundo dentro de outro mundo, os dois autores tomam, por exemplo, a realidade aparente como meio de passagem para outro lugar. O duplo é criado a partir da refração, um palíndromo da realidade. $\mathrm{Na}$ linha R 21, de Avalovara, por exemplo, a duplicidade aparece na construção do viaduto Santa Efigênia, simbolizando o verter da ideia em criação do texto por meio da palavra forjada. 
Eis um W, vegetal e zoológico (gaviões nas escamas das serpentes, bodes nas penas dos gaviões e girassóis nos chifres dos bodes), um $\mathrm{W}$ oscilante, os duplos vértices da base emaranhados entre os ferros do viaduto Santa Efigênia. Os dois arcos sobre os quais se apóia o viaduto parecem abrir-se com o peso do arcabouço e dos ônibus lotados. Rasgando-se nos rebites que estouram como botões numa túnica estreita, ergue-se o W, desprende-se e tomba, estandarte sem .mastro, sobre as fuliginosas árvores da praça e nas copas sem viço floresce uma primavera breve e inesperada (LINS, 1973, p.368).

Em 1Q84, a duplicidade também é reflexo do real, de um tempo e de um espaço conhecidos. No romance, as luas apresentam parelhas do mundo disforme. Não obstante, é geometricamente coerente e perceptível aos olhos dos personagens. Eclode, a partir do inconsciente, a consciência interior, aproveitando novamente a fala de Bergson. A luz se apresenta, ainda que no instante de um relampaguear, uma nova maneira de enxergar o derredor.

No céu havia duas luas: uma pequena e outra grande. As duas estavam emparelhadas. A lua grande era a mesma que ela (Aomame) estava acostumada a ver. Era quase uma lua cheia e de cor amarelada. Mas, ao lado dessa, havia uma outra, bem diferente. Uma lua que ela nunca tinha visto antes. Tinha o formato irregular e sua cor era levemente esverdeada, como se tivesse a superfície coberta por musgos. Era o que a sua vista captava (MURAKAMI, 2012, p. 276 - tomo I).

Nota-se, porquanto, que a ramificação da abordagem do tempo e do espaço pode ser bem mais construída do que se supõe em ambos os romances. Há um caminho, e em seus meandros estão as possíveis manifestações, as revelações da palavra de cada um dos personagens, bem como suas invenções. Nesse sentido, na revelação surge um novo mundo, corroborando com a afirmação de Mircea Eliade:

o mundo "fala" ao homem e, para compreender essa linguagem, basta-lhe conhecer os mitos e decifrar os símbolos (...) em última análise, o Mundo se revela enquanto linguagem. Ele fala ao homem através de seu próprio modo de ser, de suas estruturas e de seus ritmos (ELIADE, 2007, p. 125).

O tempo e o espaço em Avalovara e em 1Q84 fazem menção a essa busca, a qual, na literatura, não se resguarda do espanto diante do maravilhoso mundo da palavra "transgredindo um espaço selado, abarco e aceito, à reveladora claridade desse relâmpago regirante que rompe - unindo-o em seguida - o véu das coisas" (LINS, 1973, p. 381). Corroborando, ainda, nesse viés de pensamento, Tengo, em 1Q84, afirma que "ao alterar a 
ordem das palavras, as imagens tornavam-se mais nítidas. E o ritmo também se tornou mais preciso" (MURAKAMI, 2013, p. 74). Ou seja, o universo antes fragmentado, é revelado. A desestabilização e simulacros dos espaços instituídos nos romances se convergem na concretude das ações, na clareza dos cenários e percursos.

A partir dessas reflexões, o estudo do romance de Osman Lins em contraposição à de Haruki Murakami, considerando, em um primeiro momento, o paradigma indiciário, como mediador, comporta-se uma sequência valiosa de estudos literário explorando com tenacidade o tempo e o espaço. A divergência de sentidos dos personagens é rompida pela tessitura do texto que elimina o risco de dispersar. No entanto, a geometria, a rigidez do tecer, em meio a uma autonomia espacial da linguagem, elabora um cenário semelhante ao "campo da matemática, o que não se pode provar não possui sentido, mas, uma vez que se prove esse algo, os mistérios do mundo passam a caber na palma da mão, como uma ostra" (MURAKAMI, 2012, p.389).

Tal processo, no entanto, não é uma definição final. $\mathrm{O}$ ir e vir nos "discursosmundos", peculiar aos estudos literários, pode legar às investigações críticas maior autonomia, pois segue conhecendo e reconhecendo novos territórios - inventados na escrita, representados pela palavra. Dessa forma, os argumentos aqui apresentados atingem uma camada, ainda iniciática, da sedimentação intercambiária de espaço e tempo em Avalovara e em 1Q84. Portanto, "o quadro ainda não está completo. (...). O quadro está longe de estar completo" (MURAKAKI, 2012, p. 415 - tomo III).

\section{Referências Bibliográficas}

BACHELARD, Gaston. A poética do espaço. 1ª . ed. São Paulo: Martins Fontes, 1993.

Charles Baudelaire - um lírico no auge do capitalismo. Obras escolhidas vol. III. $3^{\text {a }}$. ed. São Paulo: Brasiliense, 1994.

BAKHTIN, Mikhail. Estética da Criação Verbal. São Paulo: Martins Fontes, 2003

BAKHTIN, Mikhail. Questões de literatura e de estética: a teoria do romance. $5^{\mathrm{a}}$. ed. São Paulo: Annablume, 2002.

BARTHES, Roland. Crítica e Verdade. São Paulo: Editora Perspectiva, 2003.

BENJAMIN, Walter. Magia e técnica, arte e política - ensaios sobre literatura e história da cultura. $2^{\text {a }}$. ed. são Paulo: Brasiliense, 1986.

BERGSON, Henri. Duração e simultaneidade. Trad. Bento Prado de Almeida Neto. São Paulo: Martins Fontes, 2006.

BHABHA, Homi K. O local da Cultura. Trad. Myriam Ávila, Eliana Lourenço de Lima Reis e Gláucia Renate Gonçalves. Belo Horizonte: UFMG, 2001.

BLANCHOT, Maurice. O espaço literário. Rio de Janeiro: Rocco, 1987.

BRUNEL, Pierre. (org.). Dicionário de mitos literários. $2^{\mathrm{a}}$. ed. Rio de Janeiro: José Olympio/ Brasília: Editora UnB, 1998. 
BRUNEL, Pierre. PICHOIS, CL. ROSSEAU, A.M. Que é Literatura Comparada? 1ª ed. São Paulo: Perspectiva, 1995.

CARVALHAL, Tania Franco. Literatura Comparada e literaturas estrangeiras no Brasil. In Revista Brasileira de Literatura Comparada Vol. 3, São Paulo: abralic, 1996.

COMPAGNON, Antoine. O demônio da teoria: literatura e senso comum. Belo Horizonte: UFMG, 2001.

ELIADE, Mircea. Mito e realidade. 6a . ed. São Paulo: Pespectiva, 2007.

. O Sagrado e o Profano: a essência das religiões. $3^{a}$. ed. São Paulo: Editora WMF, Martins Fontes, 2010.

FERNANDES, Ronaldo C. O narrador do romance: e outras considerações sobre o romance. Rio de Janeiro: Sette Letras, 1996.

FOUCAULT, Michel. O que é um autor? In Ditos e escritos: estética - literatura, música e cinema (vol. III). Rio de janeiro: Forense Universitária, 2001. p. 264-298.

GINZBURG, Carlo. Mitos, Emblemas, Sinais: morfologia e história. São Paulo: Companhia das Letras, 2009.

. O fio e os rastros: verdadeiro, falso, fictício. São Paulo: Companhia das Letras, 2007.

GHYKA, Matila. The Geometry of Art and Life. New York: Dover Publications, 1977.

HAMBURGER, Käte. A lógica da criação literária. 2a ed. São Paulo: Perspectiva, 1986.

HALL, Stuart. A identidade cultural na pós-modernidade. Rio de Janeiro: DP\&A, 2006.

LINS, Osman. Avalovara. São Paulo: Melhoramentos, 1973.

. O Desafio de Osman Lins. In.: LINS, Osman. Evangelho na taba: novos problemas inculturais brasileiros. São Paulo: Summus, 1979. p. 211-235.

. Lima Barreto e o espaço romanesco. São Paulo: Ática, 1976 (Ensaios, 20).

MURAKAMI, Fuminibu. Postmodern, feminist and postcolonial currents in contemporary Japanese culture. London: Routledge, 2005.

MURAKAMI, Haruki. 1Q84.São Paulo: Alfaguara, 2012 - tomo I.

1Q84.São Paulo: Alfaguara, 2013 - tomo II.

1Q84 .Portugal: Casas das Letras, 2012 - tomo III.

NITRINI, Sandra. Poéticas em confronto: Nove, novena e o novo romance. São Paulo: HUCITEC; Brasília: INL, Fundação Nacional Pró-Memória, 1987.

RICOEUR, Paul. Tempo e narrativa II. Campinas, SP: Papirus, 1995.

Tempo e narrativa III. Campinas, SP: Papirus, 1997.

SEATS, Michael. Murakami Haruki: the simulacrum in contemporary Japanese culture. USA, Lexington Books, 2009. 